\title{
Time of closure of ductus venosus in term and preterm neonates
}

\author{
M Kondo, S Itoh, T Kunikata, T Kusaka, T Ozaki, K Isobe, S Onishi
}

\begin{abstract}
Aim-To investigate the relation between gestational age, birth weight, and antenatal corticosteroid administration and the time of ductus venosus closure.

Methods-Ninety eight neonates of 30-41 weeks gestational age were studied by daily ultrasonography until ductus venosus closure.

Results-In neonates of 30-33 weeks gestational age, the ductus venosus closed at 6.0 (2.4)days (mean (SD)); in those of 34-36 weeks gestational age, it closed at 6.1 (2.8) days; and in those of 37-41 weeks gestational age, it closed at 4.2 (2.1) days. The effect of antenatal administration of corticosteroids on the time of closure was also investigated in neonates of 30-34 weeks gestational age. Closure occurred by 5.5 (2.4) days in the group given corticosteroids compared with 7.5 (2.1) days in the remainder.

Conclusions-The ductus venosus closed sooner after birth in neonates of greater gestational age or higher birth weight. Antenatal corticosteroid administration had a significant effect in promoting closure.

(Arch Dis Child Fetal Neonatal Ed 2001;85:F57-F59)
\end{abstract}

Keywords: ductus venosus closure; antenatal corticosteroids; gestational age; birth weight

The adaptation of the respiratory, circulatory, endocrine, metabolic, and nervous systems from the intrauterine to the extrauterine environment must be accomplished dynamically and smoothly at birth. The adaptation of the postnatal circulatory system is the most abrupt and dynamic of these changes. There are three specific vascular shunts in the fetal period: the foramen ovale, which by closing separates the left and right heart systems; the ductus arteriosus, which separates the pulmonary and systemic circulation; the ductus venosus, which separates the hepatoportal and systemic circulation. The pathophysiology and mechanism of closure and the pharmacological manipulation of the ductus arteriosus have been studied in detail. The ductus venosus, on the other hand, has been the subject of very little study because it is regarded as having little pathophysiological significance. A functionally patent ductus venosus was found to shunt at least $25 \%$ of the total portal blood flow in $50 \%$ of lambs between the second and sixth days of life, ${ }^{1}$ which is a level that cannot be ignored. Moreover, the early postnatal period is an unstable phase for the respiratory and circulatory systems and often a period of frequent drug treatment. In addition, if feeding is started from an early age, liver metabolism and other factors affect ductus venosus patency, and clinically there is the possibility of deleterious effects on the body from endogenous and exogenous toxic substances.

The purpose of this study was to investigate the relation of gestational age and birth weight to the time of functional closure of the ductus venosus, as well as whether or not antenatal administration of corticosteroids affects the time of closure.

\section{Materials and methods}

The subjects were 98 neonates of 30-41 weeks gestational age, who were in the Perinatal Center of the Ehime Prefecture Central Hospital between June 1995 and December 1997. Ultrasound examinations were conducted once a day to determine whether or not the ductus venosus had functionally closed. Neonates with multiple anomalies, chromosomal abnormalities, severe infection, or seizures were not included. The protocol was approved by the local ethics committee. The parents of the neonates studied were fully informed about the study. The mean gestational age of the subjects was 35.9 weeks (range 30.0-42.3). They were separated into three groups on the basis of gestational age: I, 30-33 weeks ( $\mathrm{n}=29)$; II, 34-37 weeks ( $\mathrm{n}=$ 33); III, 37 weeks and above $(n=36)$. The mean birth weight of the subjects was $2094 \mathrm{~g}$ (range 980-4015). The 29 neonates from group I were separated into those who were given antenatal corticosteroids and those who were not. Welch's $t$ test, with a significance level of $\mathrm{p}<0.05$, was used for statistical analysis.

All neonates were examined by colour and pulsed Doppler sonography using a sonography unit (SSD870; Aloka, Tokyo, Japan) with a $5 \mathrm{MHz}$ transducer. Patency of the ductus venosus was shown by a downward blood flow from the portal sinus to the inferior vena cava, using ultrasonography with the beam directed from the xiphoid process toward the right scapula (fig 1). Daily measurements were continued for each infant until it was confirmed that the ductus venosus had closed. The time of functional closure of the ductus venosus was taken as the day on which blood flow was no longer detected in the ductus venosus by colour Doppler image, and confirmed by finding no measurable blood flow for two days. These studies were performed by one neonatologist (MK). 

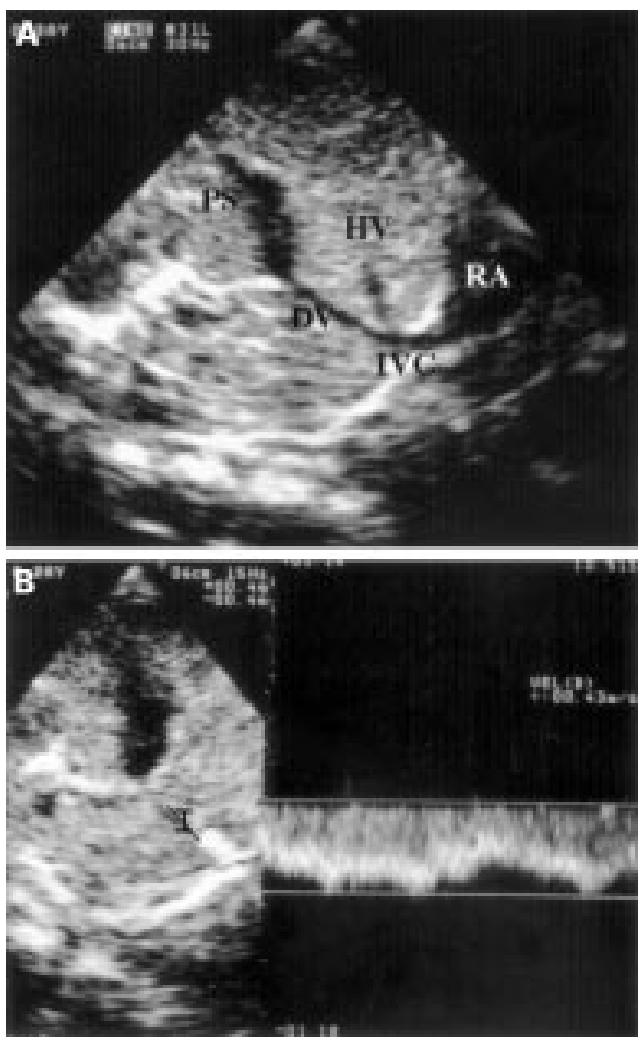

Figure 1 (A) Sagittal sonogram showing the ductus venosus (DV) between the portal sinus (PS) and the inferior vena cava (IVC). HV, hepatic vein; $R A$, right atrium. (B) Pulsed Doppler sonogram showing a constant venous waveform below the baseline, confirming cephalic flow.

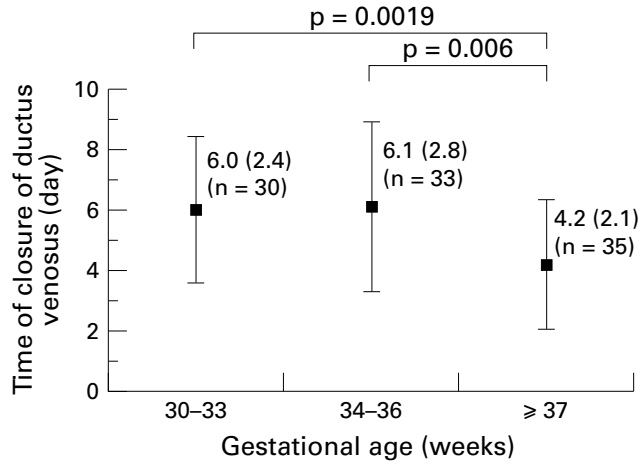

Figure 2 Relation between gestational age and the time of ductus venosus closure (days). The ductus venosus closed at a significantly later time after birth in infants in groups I (30-33 weeks gestational age) and II (34-37 weeks gestational age) than in those in group III ( $\geqslant 37$ weeks gestational age). Data are shown as mean (SD).

\section{Results}

As shown in fig 2, the ductus venosus closed at a significantly later time after birth in the infants in groups I and II than in those in group III. However, there was no significant difference between groups I and II. In groups I and II, the ductus venosus closed later in the neonates with lower birth weights (table 1).

Twenty one of the neonates in group I were given antenatal corticosteroids and eight were not. There was no significant difference between these two subgroups in either mean (SD) gestational age (32.4 (1.2) v 32.2 (1.8) weeks respectively) or birth weight (1641 (358) $v 1398$ (277) g). The time of closure was
Table 1 Time to closure of ductus venosus in infants heavier and lighter than the median body weight for each gestational age group

\begin{tabular}{lll}
\hline & Heavier & Lighter \\
\hline Group I & $6.0(2.5)$ & $6.4(3.1)$ \\
Group II & $5.7(2.0)$ & $6.3(2.3)$ \\
Group III & $4.2(2.4)$ & $4.2(1.7)$ \\
\hline
\end{tabular}

Values are expressed as days after birth and are means (SD). Group I, 30-33 weeks gestational age $(n=29)$; group II, 34-37 weeks gestational age $(\mathrm{n}=33)$; group III, gestational age $\geqslant 37$ weeks $(n=36)$.

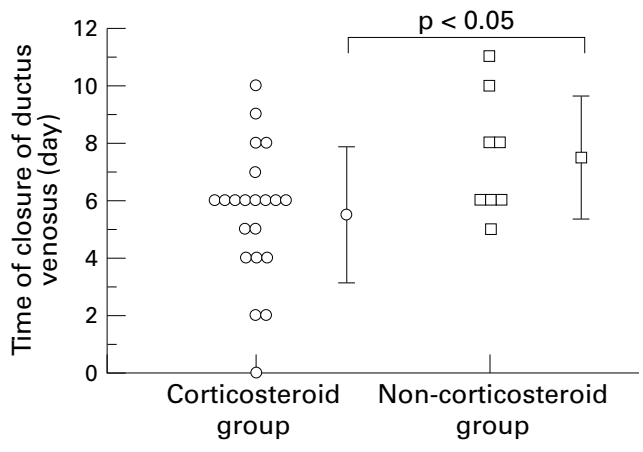

Figure 3 Time of closure of ductus venosus in relation to antenatal corticosteroid administration in neonates of 30-33 weeks gestational age. Data are shown as mean (SD).

significantly earlier in the group that received antenatal corticosteroids (5.5 (2.3) $v 7.5$ (2.1) days) (fig 3).

\section{Discussion}

The ductus venosus, which plays a key role in adaptation of hepatic circulation to postnatal metabolic function, has not been fully studied, and the time and mechanism of closure remain unclear. In a study using cineangiography, Lind $^{2}$ reported functional closure about 10 minutes after birth. Using hepatoangiography, Onishi ${ }^{3}$ showed functional closure within one week of birth in 153 neonates. Meyer and $\mathrm{Lind}^{4}$ reported that the ductus venosus closes functionally soon after birth, but that anatomically it does not close for 15-20 days. Linde et a 5 found that a catheter could pass through the umbilical vein of $64 \%$ of infants within six days of birth, but could not pass through thereafter. Among recent ultrasonographic investigations, one by Ishii et $a l,{ }^{6}$ using an ultrasonographic and pulsed Doppler method with 18 healthy term neonates, showed that the ductus venosus closes within 138 hours of birth. In similar studies, Loberant et $a l^{7}$ found that the ductus venosus was still open in $68 \%$ of infants six to seven days after birth and in $30 \%$ of infants 9-10 days after birth, while Fugelseth et al found it was open in $66 \%$ of infants at 4-5 days of age, and $22 \%$ at 7 days of age. In the present study, the ductus venosus closed between day 0 and 10 , with a mean (SD) of 4.2 (2.3), in neonates of gestational age $\geqslant 37$ weeks, which is nearly the same as the results of Ishii et $a l^{6}$ and Fugelseth et al. ${ }^{8}$ Our results also show that the ductus venosus tends to close later in neonates of shorter gestation or lower birth weight. In a study of neonates of 32 weeks gestation by Fugelseth et $a l,{ }^{9}$ the ductus venosus had closed by day 8 in $40 \%$ and by day 18 in 
$88 \%$ - that is, in $50 \%$ of neonates by about day 8. With measurements every three to four days, Loberant et $a l^{10}$ reported that the ductus venosus closed within 6-10 days in infants of gestational age 33-36 weeks, and within 10-14 days in those of gestational age 28-32 weeks. The time of closure in our study was therefore somewhat earlier than in other reports, which may be because our results were more precise, the scans being performed every day. Other possible reasons are differences in race or neonatal care. In any case, it is clear that the ductus venosus closes later in preterm neonates than in term neonates. If the ductus venosus remains open, it may lead to conditions such as galactosaemia and hepatic encephalopathy. ${ }^{11} 12$ It is also possible that it contributes to other ailments, so further close study is required.

Adeagbo et $a l^{13}$ and Yokozawa et $a l^{14}$ have investigated the response of the ductus venosus to drugs. They showed that, as for the ductus arteriosus, prostaglandin acts to keep the ductus venosus open, and cytochrome P450 haemoprotein and thromboxane $\mathrm{A}_{2}$ promote its closure. In this study, we investigated whether or not antenatal maternal corticosteroid affected the time of closure, and found that the ductus venosus closed earlier in the neonates from group I who were exposed to antenatal corticosteroids. Of the 33 infants in group II, nine received antenatal corticosteroids. No significant difference in the time of closure of the ductus venosus was found between the group that received antenatal corticosteroids and the group that did not.

The effects of steroids on patent ductus arteriosus have been well reported. ${ }^{15-17}$ The mechanism is thought to be that the steroids induce lipocortin within the cell, which in turn inhibits phospholipase $\mathrm{A}_{2}$ and lowers prostaglandin production. Coceani et $a l^{18}$ reported that the $\alpha$ adrenoceptor participates in closing the ductus venosus. Stein et $a l^{19}$ showed that the administration of steroid hormones to ewes before they give birth to premature lambs promotes the mature function of adrenergic receptors. From this, it may be assumed that the reason for earlier closure of the ductus venosus is inhibition of prostaglandin synthesis caused by the antenatal corticosteroids, and that closure is promoted by the increase in and mature activity of $\alpha$ adrenoceptors in the ductus venosus. However, it is also possible that the ductus venosus closes earlier as an indirect result of the administration of corticosteroids for the early stabilisation of circulation dynamics. In any case, further study is required on the time and mechanism of the closure of the ductus venosus in the postnatal adaptation of the neonatal hepatic circulation.

1 Botti JJ, Edelstone DI, Caritis SN, et al. Portal venous blood llow distribution to liver and ductus venosus in newborn ambs. Am $\mathcal{F}$ Obstet Gynecol 1982;144:303-8.

2 Lind J. Human fetal and neonatal circulation. Eur 7 Cardiol 1977;5:265-81.

3 Onishi S. Postnatal circulatory observations of the liver in the newborn infants. The fournal of the Nagoya City University Medical Association 1966;16:953-72.

4 Meyer WW, Lind J. Postnatal change in the portal circulation. Arch Dis Child 1966;41:606-12.

5 Linde LM, Higashino SM, Berman G, et al. Umbilical vessel cardiac catheterization and angiocardiography. Circulation 1966;34:984-8

6 Ishii Y, Terushita M, Kondo M, et al. Time course of functional closure of the ductus venosus in the healthy newborns by ultrasonographic and pulsed doppler method. Fournal of the Fapan Society for Premature and Newborn Medicine 1992;4:238-43.

7 Loberant N, Barak M, Gaitini D, et al. Closure of the ductus venosus in neonates: findings on real-time gray-scale, color-flow doppler, and duplex doppler sonography. $A m \mathcal{F}$ Roentgenol 1992;159:1083-5.

8 Fugelseth D, Lindemann R, Liestol K, et al. Ultrasonographic study of ductus venosus in healthy neonates. Arch Dis Child Fetal Neonatal Ed 1997;77:F131-4.

9 Fugelseth D, Lindemann R, Liestol K, et al. Postnatal closure of ductus venosus in preterm infants $\geqslant 32$ weeks: closure of ductus venosus in preterm infants $\geqslant 32$ weeks:
an ultrasonographic study. Early Hum Dev 1998;53:163-9.

10 Loberant N, Herskovits M, Barak M, et al. Closure of the ductus venosus in premature infants: findings on real-time gray-scale, color-flow doppler, and duplex doppler sonography. Am f Roentgenol 1999;172:227-9.

11 Misawa S, Takasago Y, Oyake Y, et al. Patent ductus venosus with hypoplastic right hepatoportal system in a young child born with asymmetric intra-uterine growth retardation. Eur F Pediatr 1992;151:569-72.

12 Gitzelmann R, Arbenz UV, Willi UV. Hypergalactosaemia and postsystemic encephalopathy due to persistence of
ductus venosus Arantii. Eur $\mathscr{f}$ Pediatr 1992;151:564-8.

13 Adeagbo ASO, Breen CA, Cutz E, et al. Lamb ductus venosus: evidence of a cytochrome P-450 mechanism in its sus: evidence of a cytochrome P-450 mechanism in its

14 Yokozawa M. Dilating effect of prostaglandin $\mathrm{E}_{1}$ for ductus venosus in neonatal rat. Acta Neonatologica faponica venosus in neo

15 Konishi T. Maturation of rat fetal ductus arteriosis by betamethasone. Acta Neonatologica faponica 1986;22:945-50.

16 Ohta A, Furukawa S. Dexamethasone therapy in preterm infants with symptomatic patent ductus arteriosus. Acta Neonat $\mathcal{J p}_{p}$ 1990;27:340-4.

17 Momma K, Konishi T, Hagiwara H, et al. Pharmacological constriction of the newborn ductus arteriosus in hypoxia. Acta Neonatologica faponica 1985;21:383-7.

18 Coceani F, Adeagbo ASO, Cutz E, et al. Autonomic mechanisms in the ductus venosus of the lamb. Am $\mathcal{f}$ Physiol 1984;247:H17-24.

19 Stein HM, Oyama K, Maetinez A, et al. Effects of corticosteroids in preterm sheep on adaptation and sympathoadrenal mechanisms at birth. Am $\mathcal{f}$ physiol 1993;264:E763-9. 